\title{
Macro y mesoclimas del altiplano andino y desierto de Atacama: desafíos y estrategias de adaptación social ante su variabilidad ${ }^{1}$
}

\author{
Hugo Romero², Pamela Smith ${ }^{3}$, Magaly Mendonça ${ }^{4}$ y Manuel Méndez ${ }^{5}$
}

\begin{abstract}
RESUMEN
Desde una perspectiva geográfica multiescalar son analizados cuantitativa y cualitativamente los factores y componentes que otorgan especificidad climática al desierto de Atacama, el más árido del mundo, y a las montañas y altiplanos andinos de las cuales dependen sus fuentes de agua, la ocupación humana y las actividades económicas, en especial la minería, que constituye la principal base del crecimiento económico de Chile. El monzón sudamericano, que asocia las masas y flujos de aire del interior del continente con el altiplano y la costa del océano Pacífico actúa como el componente macroclimático más relevante, mientras a mesoescala son las condiciones topoclimáticas, asociadas a la altura, exposición y orografía de los relieves, las que determinan la disponibilidad de agua en los paisajes. La demanda de recursos hídricos generada por el auge minero y las estrategias de adaptación de las comunidades indígenas ante las variabilidades climáticas condicionan el significado de los socioclimas, en que los elementos naturales y socioeconómicos deben ser integrados.
\end{abstract}

Palabras clave: Multiescalaridad, climatología, Monzón Sudamericano, Desierto de Atacama.

\begin{abstract}
From a geographical perspective are multiscalarity analized quantitative and qualitative factors and components that give specificity to the climate of the Atacama Desert, the driest in the world, and to Andean mountains and plateaus from which depend on water sources, human settlement and economic activities, especially mining, which is the main basis for the economic growth of Chile. The South American monsoon, which brings together air masses and flows from continental inland, towards altiplanos and the Pacific coast, acts as the most important macroclimatic component, while meso-scale topoclimatic conditions, associated with exposure, altitude and topography of reliefs, determine water in the landscapes. The demand for water generated by mining boom and the adaptation strategies of indigenous communities to cope with climate change and variability provide the meaning and significance to socioclimates, which natural and socio-economic elements should be interdisciplinary and scalarly integrated.
\end{abstract}

Key words: Multiscalarity, Climatology, Tropical Monzoon, Desierto de Atacama.

\footnotetext{
1 Resultados de Proyecto VID Universidad de Chile "Desarrollo de capacidades de adaptación de las comunidades altoandinas al cambia climático. Una propuesta didáctica para su comprensión y gestión" y FONDECYT N 1120204 "Análisis Multiescalar de los Cambios Climáticos y su consideración en la Evaluación Ambiental Estratégica del Desarrollo Regional Sustentable del Altiplano del Norte de Chile". Artículo recibido el 30 de enero de 2012, aceptado el 31 de enero de 2013 y corregido el 30 de mayo de 2013.
}

2 Departamento de Geografía, Universidad de Chile (Chile).E-mail: hromero@uchilefau.cl

3 Departamento de Geografía, Universidad de Chile (Chile). E-mail: pamelasmit@gmail.com

4 Departamento de Geociências, Universidade Federal de Santa Catarina (Brasil).

E-mail: magaclimatologica@gmail.com

5 Departamento de Geografía, Universidad de Chile (Chile).

E-mail: mendez.diaz.manuel@gmail.com 
"Se ha dicho a menudo que el Hombre no está solamente condicionado por el clima, sino que él, a su vez, lo trabaja y transforma. Pero esto es ignorar la verdadera naturaleza del clima. El Hombre aprehende el clima de sí mismo... El clima no existe aparte de la historia, ni la historia aparte del clima. Esto puede ser solo comprendido desde la estructura fundamental de la existencia humana" (Natsuji, 1961).

La variabilidad de los climas es una de las incertidumbres que toda sociedad debe enfrentar en su vida cotidiana, mediante complejos procesos de aprendizaje, adaptación y mitigación. Los cambios y variabilidades climáticos pueden ser definidos como uno de los elementos que explican la diferenciación espacial de los paisajes naturales y culturales; es evidente que los climas constituyen además recursos naturales en sí mismos, debido a los servicios ambientales que ofrecen, y a los que derivan de sus características, especialmente en términos de acumulaciones de calor, precipitaciones y fuentes de agua, capacidad de los vientos para depurar la atmósfera, confort térmico, etc. Parece ser preferible concentrarse en las variabilidades climáticas, espaciales y temporales, que en tendencias de mediano y largo plazo. Ello, porque la sociedad incorpora al clima en sus acciones cotidianas y tiene que dar cuenta de la necesidad de enfrentar con éxito a los riesgos derivados de su variabilidad, como sequías, inundaciones, olas de frío y calor, tormentas, y además de disponer de la capacidad organizativa para distribuirlos socialmente en forma equitativa y justa. Si ello no sucede, solo unos pocos tendrán acceso a los lugares climáticamente más seguros o bien podrán emplear sus recursos y beneficios en función de sus propios intereses, agregando al clima como otro de los componentes de la inequidad social que define nuestra geografía. De allí que parezca igualmente importante preocuparse de la aplicación de los modelos de cambio climático de gran escala, como observar la participación del clima en la reconfiguración de los espacios naturales, económicos y sociales.

El desierto de Atacama, localizado en parte en el norte de Chile, constituye una paradoja geográfica en la medida que conjuga por un lado, lugares donde nunca llueve, y por lo tanto el agua es el recurso natural más escaso, lo que constituye una severa limitación para su ocupación biológica y humana; mientras, por otro, en estos paisajes hiperáridos, concentra una de las mayores riquezas minerales del mundo en términos de cobre, molibdeno, plata y oro, cuya explotación requiere grandes cantidades de recursos hídricos y atrae a las más grandes empresas transnacionales dada su abundancia y calidad. Adicionalmente, el desierto de Atacama ha sido testigo de la más antigua ocupación humana por parte de las etnias aimara y atacameña, que se instalaron en esos parajes hace más de diez mil años.

La climatología del desierto de Atacama es el resultado de un complejo y dinámico sistema de relaciones multiescalares, comandadas a macroescala por el Monzón de América del Sur y sus interacciones espacio-temporales (teleconexiones) con la Oscilación del Sur (Fenómenos El Niño-La Niña), la Oscilación Decadal del Pacífico y la Oscilación Antártica (Romero et al., 2012). Este complejo sistema océano-atmósfera, determina a su vez, la ocurrencia de Iluvias y nevazones sobre las montañas y altiplanos andinos, que bordean por el oriente el desierto de Atacama, que aunque muestran una gran irregularidad interanual, constituyen, las únicas fuentes de agua dulce que hacen factible la ocupación humana de estos territorios.

A mesoescala, la topoclimatología de cuencas destaca el rol de factores geográficos más específicos de los lugares, tales como la altura, exposición y coherencia del relieve, la continuidad espacial de los sistemas de drenajes superficiales y subterráneos que vinculan las tierras altas y bajas, permitiendo que el agua alcance las depresiones interiores, e incluso la costa del desiero. Gracias a ello ha sido posible el establecimiento de la población y el crecimiento de ciudades como Arica, Iquique, Antofagasta, Calama y Copiapó, además de oasis como Quillagua, Pica o San Pedro de Atacama. A escala local, hondonadas y cerros, laderas y planicies, salares y lagunas, valles y mesetas, generan condiciones topoclimáticas, y asociadas a ellas, características hídricas y vegetales que son responsables de la alta diversidad ecológica de los paisajes, los que a su vez, alcanzan una alta variabilidad espacial en cortas 
distancias, particularmente en los valles y altiplanicies. Los paisajes más favorecidos térmica e hídricamente son reconocidos por el conocimiento local de sus habitantes ancestrales, los que enfrentan crecientemente la competencia por su control de parte de agentes externos, que intentan apropiarse de ellos para incorporarlos a la producción de bienes globales. El territorio del desierto de Atacama y sus bordes se ha transformado en un área de competencias y colisiones -especialmente por la posesión del agua-, generando un serio problema que aún espera ser resuelto por las autoridades y políticas públicas. El conocimiento multiescalar de las potencialidades y limitaciones de los climas es parte relevante de la sustentabilidad de los paisajes naturales y culturales, en medio de un proceso generalizado de privatizaciones (de las tierras, minerales, aguas, paisajes, culturas y biodiversidad) y de su transformación en comodities (bienes que se transan libremente en el mercado y cuyo precio refleja exclusivamente la relación entre su oferta y demanda). La competencia territorial por la posesión de los climas entre los espacios geoestratégicos del capital transnacional minero, por ejemplo, las áreas agrícolas de subsistencia de los habitantes locales y los circuitos de trashumancia ganadera de las comunidades indígenas, indican el significado social que han adquirido las condiciones atmosféricas regionales, de tal manera que es posible reconocer socioclimas o climas locales directamente asociadas a los territorios apropiados por cada uno de los actores sociales mencionados.

Siendo la disponibilidad de agua indudablemente el problema ambiental más importante del desierto de Atacama, Ilama poderosamente la atención el escaso conocimiento que existe sobre la relación entre recursos hídricos y variabilidad climática. La cantidad, calidad y edad de las aguas ha ocupado parte importante de los aportes de la geografía física y de la climatología a los estudios regionales, pero se sabe poco sobre el balance hídrico a escala de cuencas, de lo que depende la posibilidad de extraer tales recursos sin dañarlos definitivamente. Cabe preguntarse si la inexistencia de informaciones precisas sobre los componentes del ciclo hidrológico a escala de cuencas en esta parte del país, así como las limitaciones que presentan sus fuentes de datos climatológicos, constituyen solo un hecho espontáneo y característico causado por el limitado desarrollo científico que presenta la geografía chilena, o si, por el contrario, se trata de un hecho político, que sobre la base del desconocimiento generalizado, pretende imponer posiciones de poder por parte de quienes poseen dichas informaciones, mientras la sociedad, al no poder disponer de ellos, carece de argumentos para defender sus intereses colectivos (Bauer, 1997 y 2004; Budds, 2004, 2008, 2009a y 2009b; Romero, 2009a y 2009b, Molina, 2012).

El análisis climático sudamericano no resulta posible si no se cuenta con una perspectiva multiescalar y ecológica social (o ecológica política), para lo cual ceñirse a las fronteras de las disciplinas o de los países, es lo menos adecuado. Los desafíos del desarrollo de Chile, basados grandemente en la suerte del desierto de Atacama, como muchos otros desafíos semejantes planteados en Sudamérica, exigen un esfuerzo de investigación científica coordinado e integrado en redes, entre los diversos países, cuya circulación atmosférica manifiesta una extraordinaria unidad, que se impone sobre visiones geopolíticas desgastadas que insisten en fortalecer las fronteras y la separación geográfica de nuestros países.

\section{Materiales y métodos}

En una primera fase se abordaron las características climáticas a diversas escalas. A escala global se han utilizado Modelos de Cambio Climático basados en la Circulación General Atmosférica y sus aplicaciones a los escenarios de cambio climático realizados por el Departamento de Geofísica de la Universidad de Chile (CONAMA, 2006). A escala regional, se consideraron métodos y modelos de downscaling y scaling up (escalamiento hacia abajo y hacia arriba), mediante los cuales los resultados de la aplicación de los modelos globales, que cubren grandes espacios, han sido complementados con la información proporcionada por las redes locales de estaciones meteorológicas a escalas de cuencas y subcuencas, con la finalidad de sistematizar el rol de los factores topoclimáticos, especialmente de la continentalidad, elevación, presencia de montañas, quebradas y planicies andinas. 
La falta de estaciones meteorológicas con observaciones de largo plazo constituye una limitación insuperable para referirse a las tendencias de cambio y variabilidad climática en el desierto de Atacama. Solo dos estaciones meteorológicas cuentan con series de datos completas de temperatura de más de treinta años, pertenecen a la Dirección Meteorológica de Chile y se localizan en Arica (18 $20^{\prime}$ S.; 58 m.s.n.m.) e Iquique (2032’'s.; 52 m.s.n.m.), ambas ciudades costeras que no representan las condiciones continentales ni altiplánicas de los climas, que son totalmente diferentes en términos de oscilación térmica diaria y anual, humedad relativa, precipitaciones, nubosidad e insolación.

Para abordar el estudio del comportamiento pluviométrico del corazón y borde altiplánico andino del desierto de Atacama se cuenta con más de veinte estaciones, de las cuales, han sido seleccionadas para el análisis aquellas que cuenten con series de datos completas a partir del año 1980 o bien que los vacíos de información que presenten no superen los cinco años y que se encuentren localizadas en transectos que cruzan de poniente a oriente las regiones de Arica y Parinacota y Tarapacá, desde los centros po- blados costeros, hasta las cuencas altiplánicas de Caquena y Cancosa, respectivamente (Figura $\mathrm{N}^{\circ} 1$ ).

Las estaciones meteorológicas localizadas en el primero de estos transectos corresponden a Arica (58 msnm), Putre (3.545 m), Chucuyo $(4.200 \mathrm{~m})$, Parinacota $(4.420 \mathrm{~m})$ y Caquena $(4.400 \mathrm{~m})$. En la región de Tarapacá se trata de Iquique (52 msnm), Cerro Colorado $(2.510 \mathrm{~m})$, Parca $(2.650 \mathrm{~m})$, Mamiña (2.730 m), Poroma (2.880 m), Cancosa (3.930 m) y Coyacagua $(4.013 \mathrm{~m})$ (Figura $\mathrm{N}^{\circ} 1$ ). Sin embargo, no todas las estaciones consideradas cuentan con registros de temperatura $y$ precipitación.

La variabilidad climática de macro y meso escala ha sido relacionada espacialmente con procesos y fenómenos socioeconómicos regionales y locales que tienen lugar en el desierto de Atacama y el altiplano chileno. En primer lugar, se localizaron las inversiones económicas y yacimientos mineros, como expresión de las demandas territoriales y competencia por el uso de los recursos naturales regionales. Adicionalmente, se consideraron las demandas territoriales causadas por las áreas públicas de conservación de la

Figura $\mathrm{N}^{\circ} 1$

Localización estaciones meteorológicas consideradas en Región de Arica y Parinacota (a) y Región de Tarapacá (b)

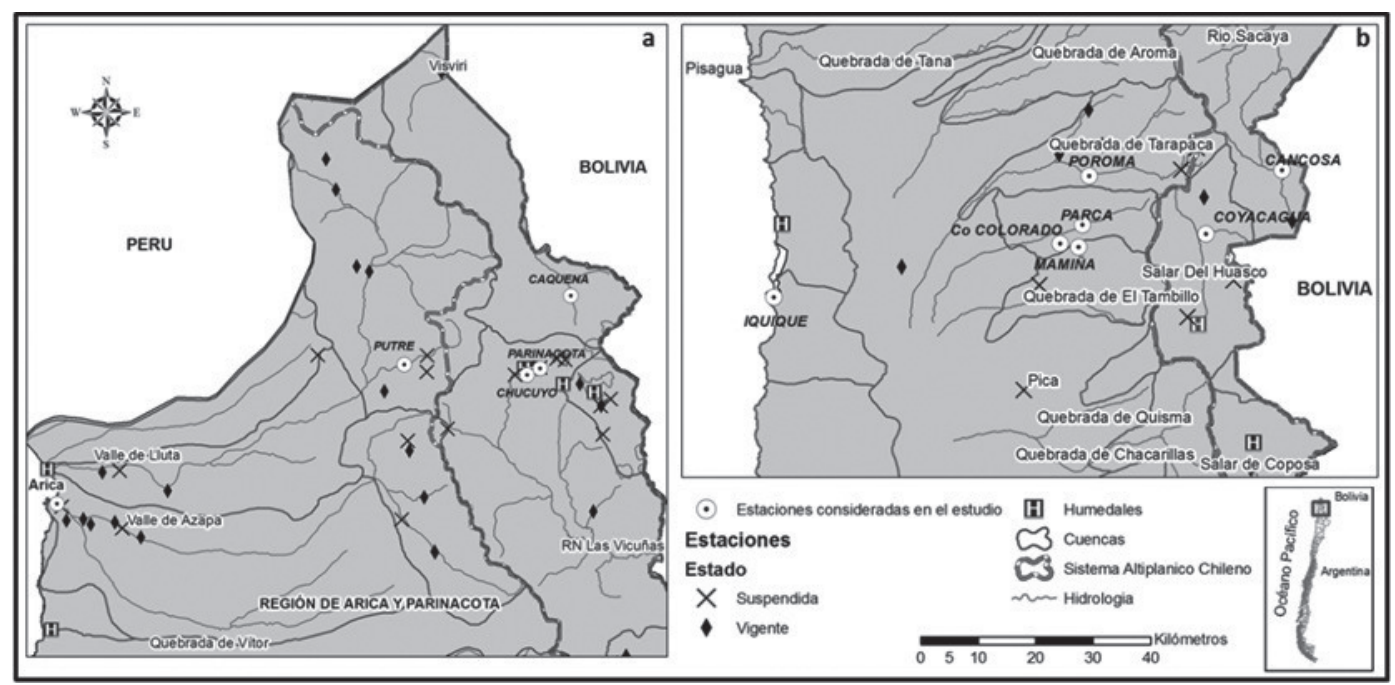

Fuente: Elaboración propia a partir de datos de la Dirección General de Aguas y trabajo en terreno. 
naturaleza, para lo cual se cartografiaron los paisajes pertenecientes al Sistema Nacional de Áreas Protegidas del Estado (SNASPE), tales como parques nacionales y reservas naturales. Los proyectos de inversión económica clasificados por sectores han sido obtenidos del Sistema de Evaluación de Impacto Ambiental (SEIA) y la localización de los yacimientos mineros corresponde a la contenida en los mapas publicados por el Ministerio de Minería. La instalación de faenas mineras representa uno de los principales desafíos para la mantención y uso adecuado de los escasos recursos hídricos del desierto y de sus áreas-fuentes, ubicadas en las altas montañas, al punto que en muchas de las cuencas de la región, estos se encuentran completamente agotados y los esfuerzos actuales se concentran en la extracción de acuíferos subterráneos. En cuanto a las áreas de conservación de la naturaleza, existe una creciente controversia en el sentido de ampliarlas para aumentar sus niveles de protección y representatividad de los ecosistemas locales y sus relaciones ecológico-sociales con las comunidades indígenas, por un lado, e intentos de reducirlas, desafectando extensas superficies con el fin de permitir la explotación de sus recursos naturales, en especial las aguas superficiales y subterráneas.

Respecto a las estrategias de adaptación sociocultural de las comunidades locales frente a los cambios y variabilidades climáticas, se han identificado y representado espacialmente los circuitos de transhumancia ganadera practicados por las comunidades indígenas de Caquena, en el altiplano de la región de Arica-Parinacota, y de Cancosa, ubicada en la misma zona de altura de la región de Tarapacá. Mediante el traslado espacial de los ganados de auquénidos, las comunidades locales reconocen la utilidad de los pisos ecológicos de las montañas y de rasgos topoclimáticos como depresiones, laderas o abrigos, tanto para proteger los animales frente al frío o sequías, como respecto a la distribución de los pastos de altura y su variabilidad estacional e interanual.

Las comunidades de Caquena y Cancosa han sido seleccionadas como estudios de caso debido a que representan dos situaciones contrastadas. En el caso de la primera no hay presencia aún de actividades mineras, de tal forma que las estrategias de adaptación se basan en los principios ancestrales ecológicosociales, que incluyen la propiedad común de tierras, pastos y aguas. En cambio, en el territorio ocupado por la comunidad de Cancosa, la Compañía Minera Cerro Colorado mantiene pozos de extracción de agua subterránea, contando con derechos constituidos por un total de $300 \mathrm{Lt} / \mathrm{seg}$. Esta extracción ha causado el desecamiento de parte del bofedal de Lagunillas, provocando no solo un severo daño ecológico -que se espera restituir en un plazo mediano-, sino que además, reduciendo significativamente las áreas potenciales de pastos y aumentando la vulnerabilidad ante los períodos recurrentes de sequía.

La información de las comunidades fue obtenida mediante diversas visitas a terreno y entrevistas en profundidad realizadas a informantes clave tales como los pastores de la zona, dirigentes comunitarios y personas ancianas. Debe hacerse notar que las informaciones cualitativas que se han obtenido proporcionan solo una mirada parcial, en la medida que de ellas surgen con facilidad importantes diferencias de opiniones entre los actores y afloran también situaciones conflictivas que se refieren, por ejemplo, a quiénes se consideran miembros reales de las comunidades y quiénes por el contrario son solo apreciados como visitantes para las festividades; entre quiénes forman parte de una u otra organización y respecto a las negociaciones que sostienen con agentes foráneos.

Respecto a la información cuantitativa, existen importantes falencias en la actualización de los datos relativos a variables sociodemográficas y socioeconómicas, así como aquellos que aluden a relaciones de propiedad y control de recursos críticos, como disponibilidad de aguas superficiales y subterráneas. Por ejemplo, se observa una gran diferencia entre la información pública sobre derechos de aguas otorgados (Catastro Público de Aguas de la Dirección General de Aguas) y los utilizados efectivamente. Para el caso de la Región de Arica y Parinacota, el Catastro Público indica que solo se han otorgado 695,94 Lt/seg, mientras que los datos obtenidos desde los registros del Conservador de Bienes Raíces de la región por Méndez et al. (2011) corresponden a 44.526,58 Lt/seg. 


\section{Macroclimatología de las relaciones entre la circulación atmosférica altiplánica y amazónica}

La alta cordillera de Los Andes representa una frontera para la circulación atmosférica, separando casi completamente el sector Este o continental, dependiente de la Amazonia, del oeste u oceánico, asociado al océano Pacífico. El tramo de la cordillera de Los Andes que se extiende entre las latitudes $18^{\circ}$ y $27^{\circ} \mathrm{S}$ -abarcando desde el límite norte de Chile con Perú hasta el límite sur del desierto en la Región de Atacama- permite el desarrollo de una zona de condiciones climáticas específicas principalmente controladas por la altitud (3.700 m.s.n.m., en promedio) y latitud (en las zonas inter y subtropical). Su localización marginal en el borde occidental del altiplano andino propiamente tal (Aceituno, 1996), le otorga importantes niveles de particularidad climática y lo distingue completamente de las demás regiones de Chile. Los sistemas atmosféricos que se desplazan desde la cuenca del
Amazonas influencian los valores de la humedad atmosférica y de las precipitaciones, que se registran en verano. En el invierno, cuando predominan los vientos del oeste, la humedad relativa es menor (Aceituno, 1996) y si bien, en general en las regiones nororientales del altiplano andino precipita en otras fechas, para el sector chileno, las Iluvias y nevazones se registran casi exclusivamente en el verano.

\section{Mesoclimatología: Efectos de la latitud,} altura y continentalidad sobre el comportamiento y variabilidad estacional de las temperaturas y precipitaciones.

\section{Comportamiento de las temperaturas}

Aun considerando la existencia de series de datos meteorológicos incompletos (con más de dos meses sin información), es posible reconocer la tendencia general que muestra que a mayor altura menor es la temperatura promedio (Figura $\mathrm{N}^{\circ} 2$ ). Las estaciones localizadas sobre los $3.000 \mathrm{msnm}$ no superan los $10^{\circ} \mathrm{C}$, comparado con las estaciones de

Figura $\mathrm{N}^{\circ} 2$

Temperatura promedio anual de estaciones localizadas en las regiones de Arica-Parinacota y Tarapacá

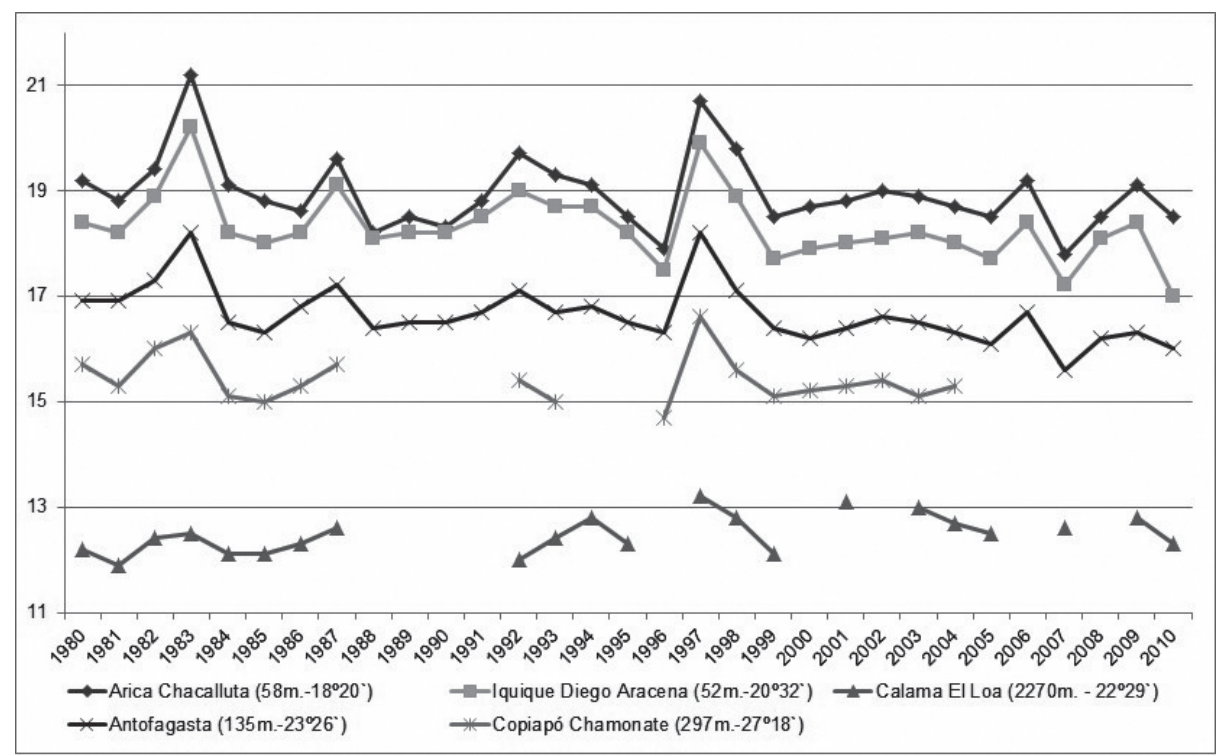

Fuente: Elaboración propia a partir de datos de los Anuarios de la Dirección Meteorológica de Chile (DMC) y de la Dirección General de Aguas (DGA). 
Arica e Iquique, ambas costeras, que poseen al menos $17^{\circ} \mathrm{C}$ como promedio anual. Se observa que los años más fríos y más cálidos son en general coincidentes en todas las estaciones de la región. Los años más calurosos coinciden con episodios significativos del fenómeno El Niño (1983, 1992, 1997, 2006 y 2009), mientras que los más fríos lo hacen con eventos La Niña (1996, 1999, 2007 y 2010).

La influencia de la temperatura de superficie del mar (TSM) y de la presión atmosférica del Pacífico es mucho más evidente en las estaciones costeras. En las estaciones de altura, como Caquena, localizada sobre los $4.400 \mathrm{msnm}$, se registra un promedio de temperatura anual cercano a $0^{\circ} \mathrm{C}$. Los valores moderados de temperatura que se registran en las zonas costeras del desierto de Atacama (un hecho climático azonal tratándose de un desierto esencialmente intertropical), se deben al alcance de la Corriente de Humboldt, por la cual masas de agua fría subantárticas son trasladadas a lo largo del litoral sudamericano, hasta Colombia. En las estaciones costeras, con series más largas y completas, se observa una diminución de las temperaturas medias a partir de 1999.

\section{Distribución regional de las precipitaciones}

El control pluviométrico ejercido por las altas presiones asociadas al Anticiclón Semipermanente del Pacífico del Sudeste y sus inversiones térmicas de subsidencia y radiación (que se deben al predominio constante de las surgencias de aguas subantárticas de la Corriente de Humboldt) impiden completamente la formación de nubes de altura y por lo tanto de ocurrencia de precipitaciones desde la costa hasta $200 \mathrm{~km}$ al interior y a lo menos $2.000 \mathrm{~m}$ de altura.

La extrema variabilidad interanual de las precipitaciones altiplánicas se manifiesta en la ocurrencia de años completamente secos, hasta otros, que en función del aumento de la altura, pueden aproximarse a $800 \mathrm{~mm}$ anuales. Los datos existentes no solo impiden registrar tendencia alguna de variación interanual, sino que implican además una altísima incertidumbre sobre la existencia de agua superficial y por ello, un aumento creciente de la presión sobre los recursos subterráneos, muchos de los cuales son de carácter fósil y por ello, no renovables.

Las anomalías de precipitación que ocurren simultáneamente en el altiplano, sur de Bolivia y centro de Argentina, tienen lugar en discordancia con el lado este del continente y del océano Atlántico subtropical. El transporte de humedad es producido por la circulación regional, que aspira el aire húmedo de la capa límite atmosférica (CLA) de la planicie continental ubicada al este de la vertiente de los Andes. Lo mismo ocurre en el lado oeste, con el transporte de aire seco del desierto costero hasta el altiplano. Estas circulaciones de escala regional son desencadenadas por el calentamiento de las vertientes cordilleranas, pero el flujo de gran escala puede modular su intensidad y duración impulsando la mezcla en el tope de la CLA. Sobre los Andes centrales el flujo medio sobre la vertiente occidental y los vientos debajo del nivel de la CLA se tornan más fuertes o más débiles, aumentando el transporte de humedad de la planicie continental que alimenta la convección profunda. Las precipitaciones también pueden originarse en la depresión continental al este de los Andes, pero alcanzan solo a la mitad del altiplano y ocurren en escalas de tiempo más cortas, de 2 a 5 días (Garreud et al., 2003).

En el altiplano andino del desierto de Atacama, las precipitaciones se concentran en los meses estivales, escapándose de esta forma del comportamiento generalizado de los climas chilenos, siempre bajo el área de influencia del océano Pacífico. Chile presenta en su parte central $\left(27-38^{\circ} \mathrm{S}\right)$ climas de tipo mediterráneo, con precipitaciones exclusivamente en los meses invernales (mayo-agosto) provocadas por los frentes polares y en la sección más austral $\left(38-56^{\circ} \mathrm{S}\right)$, precipitaciones durante todo el año debido a la circulación de los oestes de latitudes templadas y subantárticas.

La concentración de las lluvias en el altiplano andino en los meses estivales depende del contenido de humedad de las masas de aire originadas sobre la planicie continental ubicada hacia el este. Sin embargo, la humedad continental es igualmente alta en la estación del invierno, por lo que se deberían 
esperar también lluvias invernales. Ello indica que las precipitaciones están controladas por cambios en la dirección del transporte del aire y no por el contenido de humedad de la región de origen (Garreud et al., 2003).

La Alta de Bolivia (AB), centro de altas presiones atmosféricas que se localiza en la atmósfera superior, está asociada, en los bajos niveles atmosféricos, con la Baja del Chaco. En el verano se posiciona entre Bolivia y el estado brasileño de Mato Grosso del Sur, después de localizarse sobre Perú y oeste da Amazonía (Alves, 2009). Representa un sistema típico y cuasi estacionario de circulación en los altos niveles atmosféricos, que resulta del aumento de la convección continental en la Amazonía, relacionada a su vez con el avance meridional de la Zona de Convergencia Intertropical (ZCIT), que en conjunto con la Corriente del Jet Subtropical atraen más hacia el sur el cinturón ecuatorial de los vientos del este. En el corazón del verano ocurre un cambio en la dirección de los flujos de aire del oeste a uno del este a $200 \mathrm{hPa}$ cerca de los $20^{\circ} \mathrm{S}$, debido a la circulación del monzón sobre América del Sur (Gan et al., 2009). Esta última consiste en reversiones estacionales en la dirección de los vientos, que causan veranos lluviosos e inviernos secos (Moran y Morgan, 1986), lo que se verifica tanto en la región centro-oeste del Brasil como en el altiplano andino. Mientras tanto, en el resto de América del Sur los vientos de los bajos niveles atmosféricos no revierten sus direcciones durante los cambios de estación.

El desarrollo del sistema del monzón sudamericano se inicia durante la primavera, debido al aumento de la convección profunda sobre el noroeste de la cuenca amazónica, que avanza en dirección al sureste de Brasil en noviembre y causa máximos totales de precipitaciones entre los meses de diciembre y febrero sobre la mayor parte de la región tropical de América del Sur (Gan et al., 2009).

En los períodos de transición desde la estación seca a la estación lluviosa y viceversa, se observan variaciones en la circulación atmosférica, como la inversión de los vientos zonales al inicio y término de la estación Iluviosa: los vientos son del este (oeste) en los bajos (altos) niveles atmosféricos durante la estación seca, y del oeste (del este) en la estación Iluviosa (Gan et al., 2004). Es decir, en la estación húmeda los vientos de los altos niveles atmosféricos (del este), suministran el aire húmedo de la convección tropical profunda que ocurre en la planicie continental, posibilitando las precipitaciones en el corazón del verano a través del Ilamado "invierno altiplánico o invierno boliviano" (Romero et al., 2011). Además de eso, el flujo de humedad que en la estación seca es perpendicular a la cordillera de los Andes al norte de los $10^{\circ} \mathrm{S}$, diez días antes del inicio de la estación Iluviosa, comienza a girar para el suroeste, favoreciendo el transporte de la humedad de la Amazonía para el centro-oeste brasileño (Gan et al., 2009).

La circulación del monzón sudamericano (como sucede con su homólogo asiático), está relacionada con las diferencias de temperatura entre tierras y mares, que en los meses más calientes crean un gradiente horizontal de presión que transporta el aire húmedo oriundo del océano hacia el interior del continente, donde en contacto con la superficie recalentada, asciende, se enfría adiabáticamente y condensa su humedad, liberando calor latente que intensifica la convección y las precipitaciones. En los altos niveles atmosféricos, esta porción de aire diverge y desciende sobre el océano más frío provocado por las aguas subantárticas del Pacífico transportadas por la Corriente de Humboldt que alcanzan la superficie por activos procesos de surgencia (Romero et al., 2011).

La reversión estacional de los vientos, que es propia de los monzones, se presenta solo en relación a los vientos zonales medios, con dirección del este en los bajos niveles (hasta $800 \mathrm{hPa}$ ) y del oeste en los niveles atmosféricos medios y altos, antes del inicio de la estación Iluviosa. Esta última tiene inicio y finaliza exactamente en el momento en que ocurre la inversión en la dirección de los vientos (Gan et al., 2009).

En el verano, las lluvias en el altiplano andino tienden a concentrarse en una semana, seguidas por un período de sequía de la misma duración. Las tempestades convectivas se organizan a mesoescala, abarcando los Andes centrales y también a escala topoclimática, 
diferenciando el comportamiento de las mesetas, laderas y ejes de drenaje fluviales de cada una de las cuencas altiplánicas. El acoplamiento de estas causas puede generar Iluvias intensas y aluviones como ha quedado dramáticamente demostrado en los valles de las regiones de Arica-Parinacota y Tarapacá el día 13 de marzo de 2012, los que arrasaron con parte importante de las viviendas y cultivos de lugares como Moquella, Camiña, Cuisama y Chapiquilta.

La condición episódica de las lluvias demuestra un incremento de la humedad que permite a las corrientes ascendentes locales generar precipitaciones. Como la precipitación episódica del altiplano andino, el monzón no es continuo durante toda la estación lluviosa, teniendo una secuencia de fases activas e inactivas, que varían en frecuencia e intensidad de un año para otro. Por ello, la estación lluviosa puede registrar precipitaciones por sobre o bajo lo normal, que es una característica de su alta variabililidad. Esta característica del monzón sudamericano identifica por lo menos uno de los mecanismos actuantes en la producción de precipitaciones en el altiplano. Aún más, cuando el monzón está en la fase activa ocurren días con poca o con mucha precipitación (Gan et al., 2009).

En los períodos en que los vientos soplan del oeste en los niveles bajos, en altura son del este y constituyen flujos zonales que Ilevan humedad al altiplano. Para Gan et al., (2009), los períodos secos observados pueden estar asociados a la intensificación de las Corrientes de Chorro de los Bajos Niveles (al este de los Andes). La fase activa también puede estar asociada a la actuación de sistemas sinópticos, frontales y de vórtices ciclónicos en los altos niveles atmosféricos, que embutidos en la Zona de Convección Tropical (ZCT) aumentan el total de las precipitaciones en la región monzónica. La ausencia de tales sistemas sinópticos disminuiría el total de precipitaciones, caracterizando la fase inactiva.

En el período activo también han sido observadas una anomalía negativa en el campo de la presión atmosférica, anomalía ciclónica en la circulación de bajos niveles y anomalía anticiclónica en la circulación de altos nive- les, observándose lo opuesto en el período inactivo. Anomalías de los vientos del oeste han sido asociadas al período activo y las del este al período inactivo del monzón, desde la región amazónica hasta la región sudeste del Brasil (Gan et al., 2009).

Al inicio de la temporada de lluvias, la ZCIT en el océano Pacífico, que se encuentra aproximadamente a $10^{\circ} \mathrm{N}$, actúa en la desestabilización de la atmósfera y la organización de la convección sobre el continente, específicamente sobre la región noroeste de la Amazonía. Esta convección sobre el continente comienza a extenderse hacia el sureste, regresando a su posición original hacia el final de la estación de lluvias, cuando está conectada a la ZCIT del Atlántico (Gan et al., 2009).

Los aportes de la ZCIT sobre la climatología del altiplano pueden ser reforzados por las Corrientes del Chorro de Bajos Niveles de América del Sur, que conforman un importante flujo meridional de aire tropical observado en la baja atmósfera (hasta $3 \mathrm{~km}$ de altura) al Este de los Andes. Este viento, que alcanza velocidades máximas en torno a los 2.000 $\mathrm{m}$ actúa como una correa transportadora de humedad desde las regiones tropicales a las subtropicales. La humedad es oriunda de los flujos de vientos alisios que pasan sobre Amazonía y de la evapotranspiración de la selva. En el desplazamiento de las corrientes de chorro del este al oeste, sufren cambios en la dirección, debido al bloqueo ejercido por la cordillera, corriendo paralelamente a ella. En el verano, entre noviembre y febrero, los flujos de la Amazonía están más intensificados, mientras que en invierno son más débiles y la humedad transportada hacia el sur es de origen oceánico asociada al ciclo anual de la alta subtropical del Atlántico Sur (Marengo et al., 2009).

La distribución espacial de las precipitaciones de las regiones de Arica y Parinacota y Tarapacá (Figura $N^{\circ} 3$ y Figura $N^{\circ} 4$, respectivamente) demuestra la influencia de la circulación atmosférica descrita. Estaciones ubicadas en la costa y bajo la influencia de la circulación del Pacífico, como es el caso de Arica, casi no registran precipitaciones, pero en las estaciones de mayor altura, bajo la influencia del monzón sudamericano, los 
montos anuales pueden superar los $700 \mathrm{~mm}$ (Figura $N^{\circ} 3$ ).

Al avanzar hacia el sur, hacia la región de Tarapacá, se produce una reducción de las precipitaciones en la medida que se aleja de las influencias amazónicas. La localización de los paisajes altiplánicos sobre 3.000 m.s.n.m. permite que reciban precipitaciones promedio de 150 milímetros anuales, como es el caso de Cancosa. Sin embargo, la localidad de Parca, localizada a 2.650 m de altura registra solo un promedio de 25 milímetros, lo que indica el rol de los factores topoclimá- ticos y en especial las barreras topográficas que se interponen entre el altiplano y los valles andinos, reduciendo las lluvias aun estando bajo la influencia latitudinal del monzón sudamericano. Las Iluvias del altiplano andino pueden ser potencializadas por la presencia de la fase fría del ENSO, como por ejemplo ocurrió los años 1984 y 2001, cuando eventos La Niña causaron precipitaciones cercanas o superiores a $100 \mathrm{~mm}$ registrados en todas las estaciones meteorológicas. Cancosa presentó valores superiores a $350 \mathrm{~mm}$ durante los dos eventos La Niña mencionados (Figura $\mathrm{N}^{\circ} 4$ ).

Figura $\mathrm{N}^{\circ} 3$

Precipitación total anual a lo largo del transecto latitudinal de la región de Arica y Parinacota

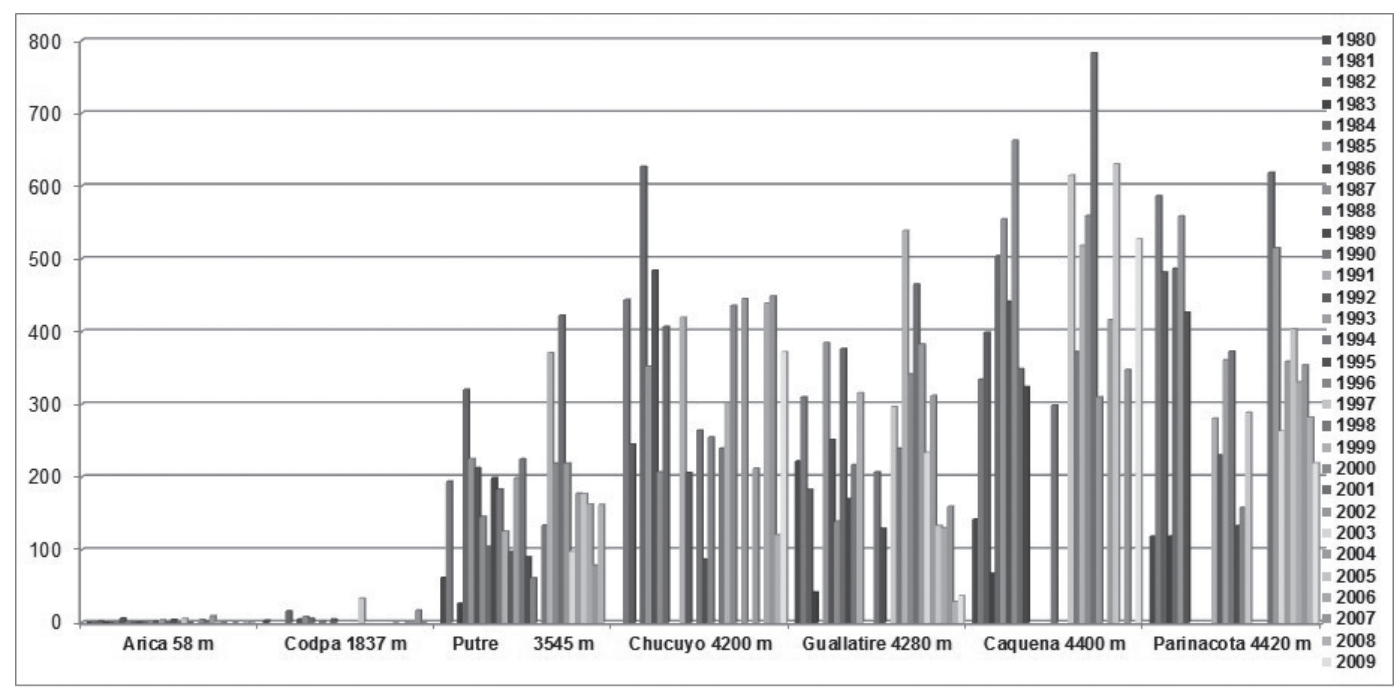

Fuente: Elaboración propia a partir de datos de los Anuarios Meteorológicos de la Dirección Meteorológica de Chile y de la Dirección General de Aguas (DGA).

\section{Variabilidad interanual}

La precipitación en los Andes centrales muestra una fuerte relación lineal con los vientos zonales de $200 \mathrm{hPa}$ sobre el altiplano, es decir, los veranos húmedos (secos) están relacionados con los flujos medios del este (oeste) en la troposfera superior, lo que sugiere que los mecanismos responsables de episodios en la escala interestacional también actúan a escala interanual. Hay veranos que registran una mayor proporción de días del viento del este y por lo tanto de lluvias. La variabilidad interanual de las precipitaciones se expresa principalmente en un incremento en el número de días de lluvia (secos) en la temporada de lluvias y no en una mayor (menor) intensidad de las precipitaciones. Las anomalías de viento zonal y el comportamiento del océano Pacífico no son independientes. Los vientos del nivel superior son parte de la amplitud de la respuesta atmosférica al patrón espacial de la temperatura superficial del mar (TSM) en el Pacífico Tro- 
Figura $\mathrm{N}^{\circ} 4$

Precipitación total anual a lo largo del transecto latitudinal de la región de Tarapacá

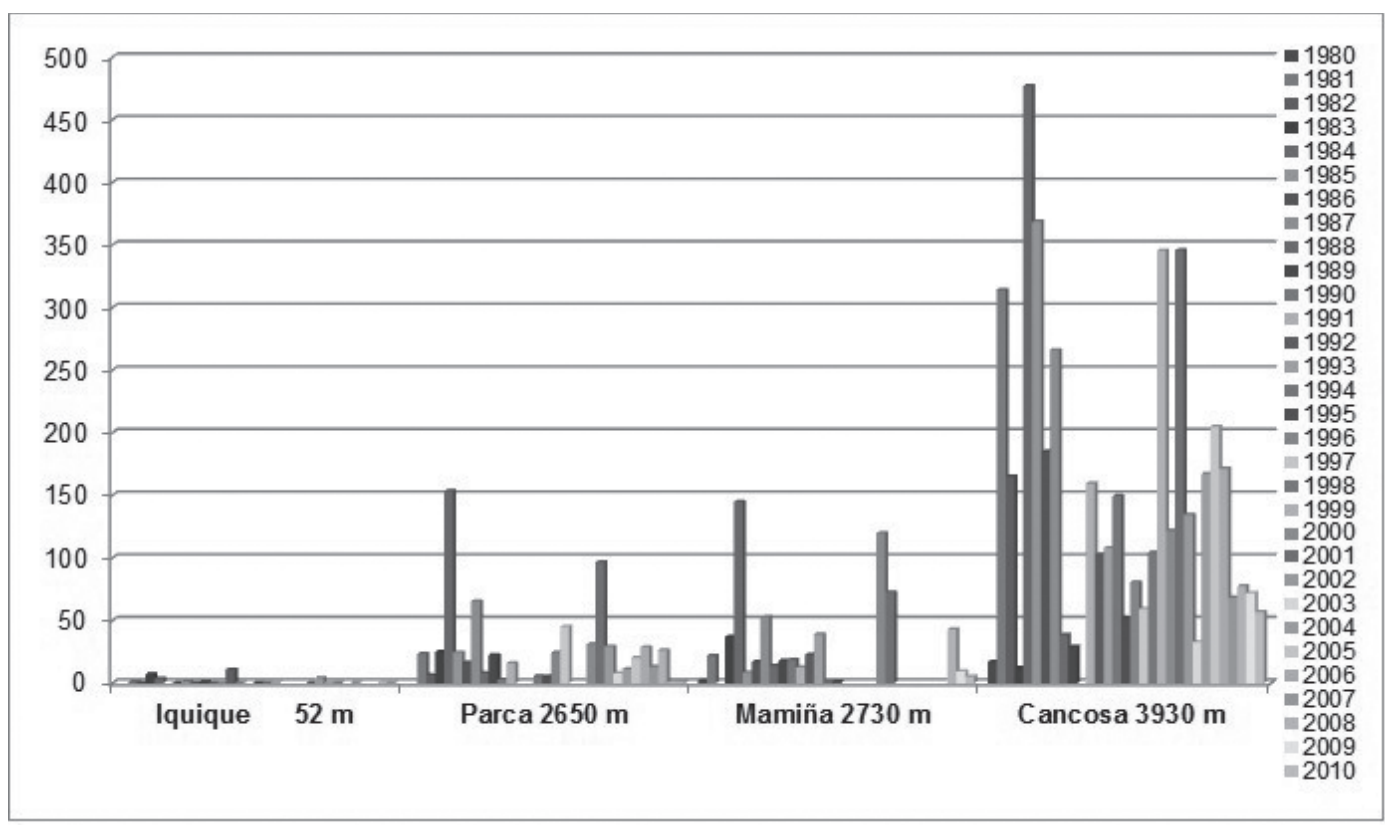

Fuente: Elaboración propia a partir de datos de los Anuarios Meteorológicos de la Dirección Meteorológica de Chile y de la Dirección General de Aguas (DGA).

pical y proporcionan la conexión física entre la forzante oceánica y el clima de los Andes centrales. Las correlaciones entre las series temporales de precipitación del altiplano y la TSM contemporánea del Pacífico, a la altura geopotencial de $200 \mathrm{hPa}$ y los vientos, muestran una influencia significativa de El Niño Oscilación del Sur (ENSO) en la precipitación registrada en los meses de diciembre, enero y febrero en el altiplano (Garreaud et al., 2003).

Existe una relación significativa entre la precipitación en el altiplano y las anomalías en los vientos zonales antes y después de El Niño, lo que es resultado de un fuerte gradiente de presión entre las latitudes tropicales y subtropicales del sur, consistente con las situaciones este/húmedo y oeste/seco derivadas de la escala sinóptica. Con el enfriamiento de la zona tropical del Pacífico (Fenómeno La Niña) hay un estrechamiento de la troposfera y por lo tanto un mayor aumento en el flujo del este hacia el Altiplano, en respuesta a las diferencias de presión y temperatura entre las latitudes tropicales y subtropicales del sur, revirtiendo el patrón durante los veranos secos. Por lo tanto la disponibilidad de humedad en las tierras bajas tropicales no es un factor dominante para regular la precipitación en el altiplano (Garreaud et al., 2003).

La correlación entre el Fenómeno ENOS y las Iluvias en el altiplano dependerá de la temperatura de la superficie del mar (TSM) en los trimestres de verano (NDE, DEF, EFM) (NOOA/NCEP, 2012). En algunos años no se verifican totales significativos de precipitación en años La Niña (1989 y 1996), pero sí en años El Niño (1987). A pesar de la importancia de las anomalías de TSM en la región ecuatorial del océano Pacífico, para la circulación de gran escala en Sudamérica, otros factores de escala global y regional también influencian la convección tropical, generando o dificultando la ocurrencia de las precipitaciones.

Algunos hechos meteorológicos de gran escala acentúan o inhiben el desempeño 
de la ZCIT, en la medida que modifican los alisios del nordeste, asociados al desplazamiento meridional de la misma. Así, con relación a las variabilidades interanuales, todo indica que si la ZCIT se mantiene al norte de la línea del ecuador en condiciones de "dipolo caliente" (aguas más calientes en el Atlántico norte), tanto en los años de la Niña como de Niños, influencia la ocurrencia de precipitaciones por debajo de la media en el nordeste de Brasil. En condiciones de dipolo frío (aguas más calientes en el Atlántico sur), la ZCIT se localiza al sur del ecuador, tanto en los años de El Niño como de La Niña, por lo cual en los primeros las precipitaciones sobre la media solo ocurren en el extremo norte de la región, mientras que en las demás áreas predominan las sequías. Bajo las condiciones de La Niña, toda la región registra anomalías positivas. Las anomalías de precipitación en el noreste brasileño también están relacionadas con los mecanismos asociados a los movimientos ascendentes y subsidentes de las células de Hadley y de Walker (Melo et al., 2009). En el altiplano, en algunos años la correlación ENSO y totales de precipitaciones implicaron montos que casi duplicaron el promedio, como fue el caso de 2001 en Caquena. En los veranos La Niña de 1984, 1999 y 2001, todas las estaciones registraron valores pluviométricos sobre el promedio, así como ocurrió en El Niño de 1987. También llovió debajo el promedio en los veranos El Niño de 1983, 1988, 1995, 2003, 2007 y 2010 y aun en los veranos La Niña de 1989, 1996, 2008 y 2009, con raras excepciones, lo que sugiere la influencia del dipolo del Atlántico, que debería ser mejor investigado para evaluar sus correlaciones con el clima del altiplano.

Con relación a las anomalía del ENSO, Lau \& Zhou (2000) constataron la contribución de las corrientes de Chorro a la convección de las masas de aire en el altiplano, debido a una gran reducción de las precipitaciones sobre la Amazonía, durante El Niño de 1997-98, asociada al desplazamiento hacia el sur de la circulación monzónica del verano de América del Sur y de sus sistemas causantes de Iluvias. En esta situación, la Alta de Bolivia fue hidrostáticamente aumentada por un camellón de altos niveles atmosféricos que se extendía desde la región de El Niño-3, en el Pacífico, hasta el altiplano andino. Esto indicaba que un intenso Chorro de Bajos $\mathrm{Ni}$ veles penetró hasta los extratrópicos y al encontrarse con los chorros subtropicales, generaron condiciones dinámicas propicias para un aumento de la convección en el altiplano (Melo et al., 2009). En la Figura $N^{\circ} 5$ a se observan totales de hasta $600 \mathrm{~mm}$ registrados el año 1997 en Caquena, cuando cabría esperar cifras inferiores debido a la correlación negativa que existe entre la caída de lluvias y el Niño en el altiplano. Por otro lado, no se observó lo mismo en Cancosa, pero sí en Parca, donde también se registraron lluvias sobre el promedio (Figura $N^{\circ} 5$ b). Ello podría estar indicando la actuación de la Corriente del Chorro a una escala topoclimática de cuencas.

El examen de las series y su comparación revela una gran complejidad de las causas de las condiciones climáticas generadoras de precipitaciones y sequías. La actuación de los sistemas productores de tiempo meteorológico no tiene las mismas consecuencias en la totalidad del altiplano, variando con la posición de las estaciones meteorológicas, continentales y costeras, su latitud y la orientación de las cuencas, demandando estudios topoclimáticos basados en una red meteorológica más amplia.

\section{Socioclimas y relaciones ecológico- sociales}

En pocos lugares del mundo el clima es tan valioso como en el desierto de Atacama y las montañas tan imprescindibles como "torres de agua". Tal como se ha visto, las precipitaciones sólidas y líquidas sobre las montañas dependen de complejas relaciones climáticas multiescalares. Uno de los efectos más relevantes de las condiciones climáticas es, por supuesto, la escasez de agua y con ello la existencia de grandes limitaciones para sostener la vida, sus habitantes y actividades económicas -que como en el caso de la minería- son vitales para Chile. La minería del desierto de Atacama provee al país de las divisas necesarias para financiar su crecimiento y cuando los precios de los minerales son altos en el mercado internacional -como sucede en la actualidad-, realizar ahorros que le han permitido significativas inversiones en infraestructura y disponer de liquidez monetaria en medio de las crisis 
Figura $\mathrm{N}^{\circ} 5$

Identificación de la actuación del Fenómeno ENOS en los veranos de 1981-2009 y su influencia en las precipitaciones totales anuales en estaciones precordilleranas (Putre y Parca) y altiplánicas (Caquena y Cancosa) en las regiones de (a) Arica y Parinacota y (b) Tarapacá
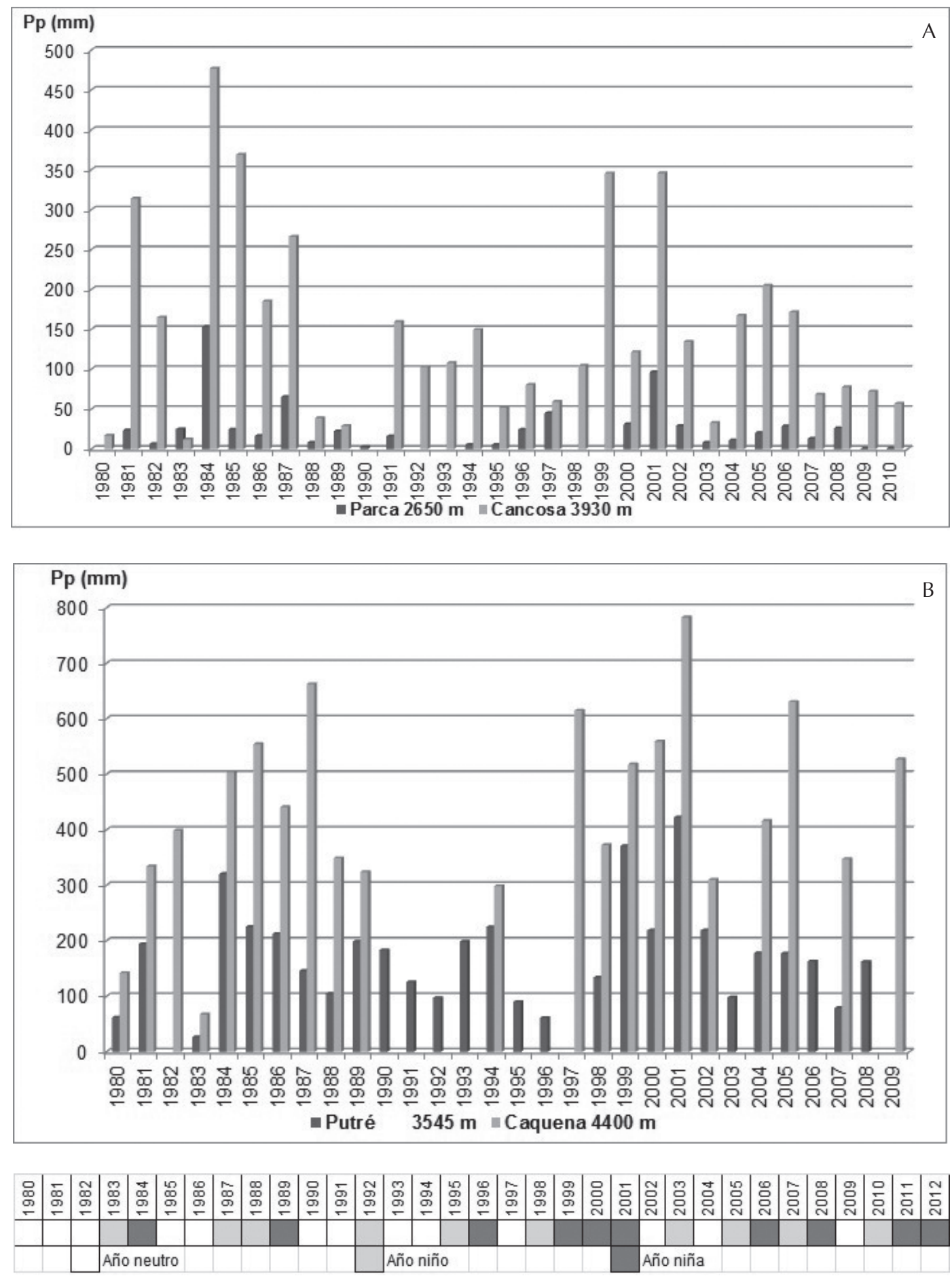

Fuente: Elaboración propia. 
internacionales. Sin embargo, y tal como se ha señalado, la ocurrencia de precipitaciones y por ello, la oferta de recursos hídricos alcanza extraordinarios niveles de incertidumbre debido a la alta variabilidad interanual y eventualmente a las tendencias derivadas de los procesos de cambio climático, cuyos modelos aplicados en esta zona del país, indican una mayor aridez que se hará presente desde mediados del presente siglo, afectando severamente las fuentes de agua altiplánicas (Romero et al., 2011).

En medio de la incertidumbre que rodea las predicciones sobre la oferta de recursos hídricos debido a la falta de información científica, la atención se encuentra focalizada sobre la demanda, especialmente porque en Chile el agua ha sido privatizada desde 1981 y constituye un bien que se transa en el mercado, sin mayor intervención del Estado ni de las políticas e instituciones públicas en su asignación. Consecuentemente, el conocimiento sobre los climas de los lugares en que se producen las precipitaciones y de aquellos en que se almacenan las aguas, superficial o subterráneamente, es una información geográfica de carácter estratégico, de la cual el Estado y la sociedad normalmente no disponen. La falta de estaciones meteorológicas, la carencia de modelos hidrogeológicos precisos o la ausencia de balances hídricos por cuencas, no son hechos que puedan ser comprendidos sin recurrir a los argumentos de la ecología política. En Chile las instituciones públicas desconocen las cantidades reales de agua que existen en sus cuencas y los modelos carecen de validación; la demanda de agua supera varias veces la recarga de muchos ríos y las extracciones clandestinas de aguas subterráneas impiden disponer de cualquier estimación acertada sobre la conveniencia de seguir o no otorgando derechos de agua por medio de los cuales las empresas privadas se transforman en propietarias de los recursos a perpetuidad. Muchas fuentes de agua se han visto completa o parcialmente dañadas por las extracciones ilegales o por errores flagrantes en los modelos hidrogeológicos. Otras veces, comunidades rurales e indígenas han perdido parte o la totalidad de sus recursos hídricos. Para la ecología política, estos problemas socioinstitucionales son elementos relevantes de los sistemas ecológico-sociales y demuestran claramente el ejer- cicio del poder de los actores. La inexistencia de información científica o la debilidad de las instituciones públicas para realizar una adecuada gestión del agua forma parte de la aplicación de los principios económicos neoliberales, por los cuales se ha intentado reducir tanto como sea posible el rol de los organismos estatales, la fortaleza de los servicios públicos y aun el financiamiento de las instituciones de investigación, tales como las universidades. El clima y el agua no son más solo recursos naturales sino que se trata de bienes sociales comodificados, privatizados y transformados en propiedad privada, sometidos al mercado y a la hegemonía de los sectores sociales más poderosos desde el punto de vista político, cultural y económico (Budd, 2009a y 2009b; Prudhan, 2009).

La apropiación de los climas por parte de los actores globales de la economía, se observa en la Figura $N^{\circ} 6$, que localiza geográficamente los proyectos de inversión que se ejecutaban entre los años 2008 y 2010 en el desierto de Atacama. Mientras en la década de 1990 las inversiones mineras más relevantes se ubicaron en las regiones más septentrionales del desierto, Tarapacá y Antofagasta, las que se ejecutan en la actualidad implican un desplazamiento hacia el sur, al incorporar activamente a la región de Atacama, en gran medida en búsqueda de nuevas reservas minerales y ante la escasez de agua.

Un primer hecho geográfico que resalta es la existencia de áreas de conservación de la naturaleza, como parques nacionales y reservas naturales en el área altiplánica y en torno a las fuentes de agua, lugar de residencia además de los pueblos indígenas y donde practican la agricultura y ganadería de auquénidos. Siendo estas las únicas fuentes de agua, su mantención y aun fortalecimiento, cubriendo áreas que actualmente no están protegidas, es un asunto muy relevante. También lo es la ocupación intensiva de las aguas superficiales y subterráneas para llevar adelante los procesos de extracción, producción, transporte y disposición final de los minerales. En el caso de la minería del cobre, los montos necesitados son muy variables y dependientes del tipo de veta que se esté explotando (óxido o sulfuro) y las condiciones geográficas del yacimiento en sí. Según estimaciones de Lagos (1997) el consumo de 
Figura $\mathrm{N}^{\circ} 6$

Localización de inversiones mineras (en millones de dólares) en el desierto de Atacama el año 2010 y su relación espacial con las áreas de protección y conservación de la naturaleza
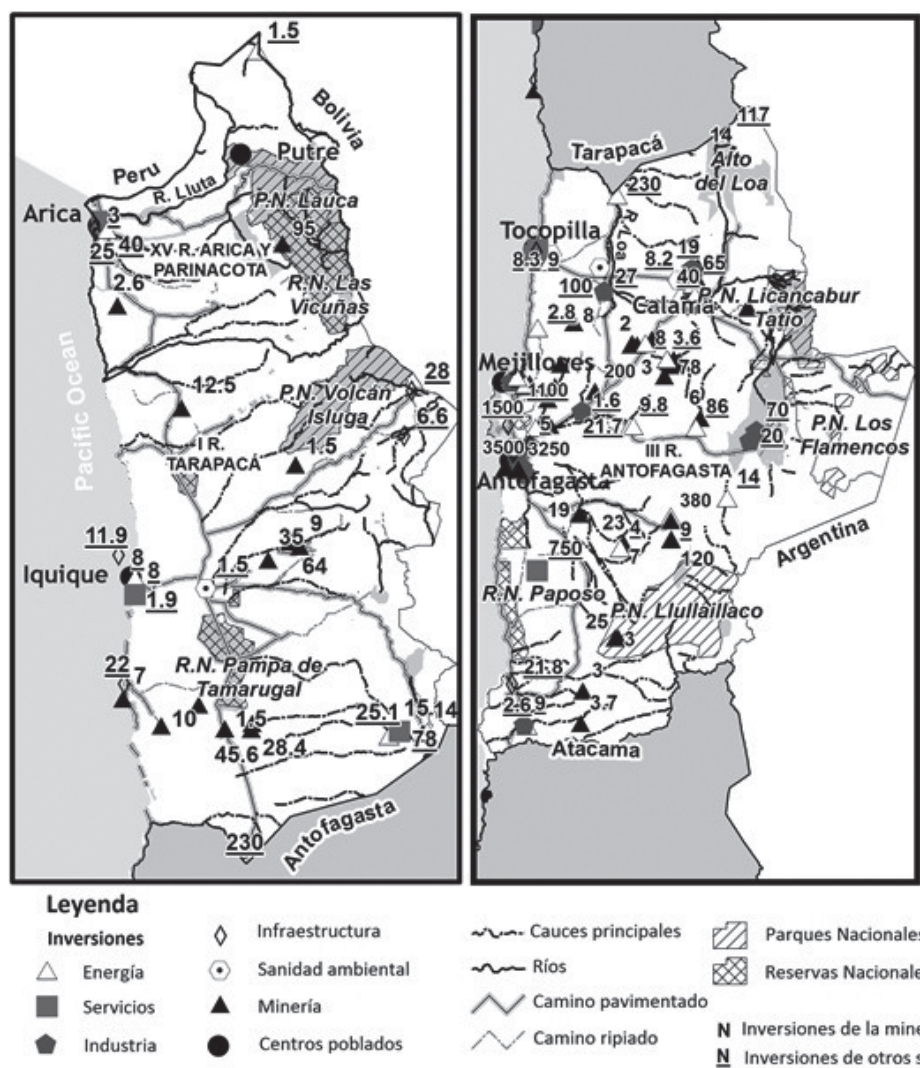

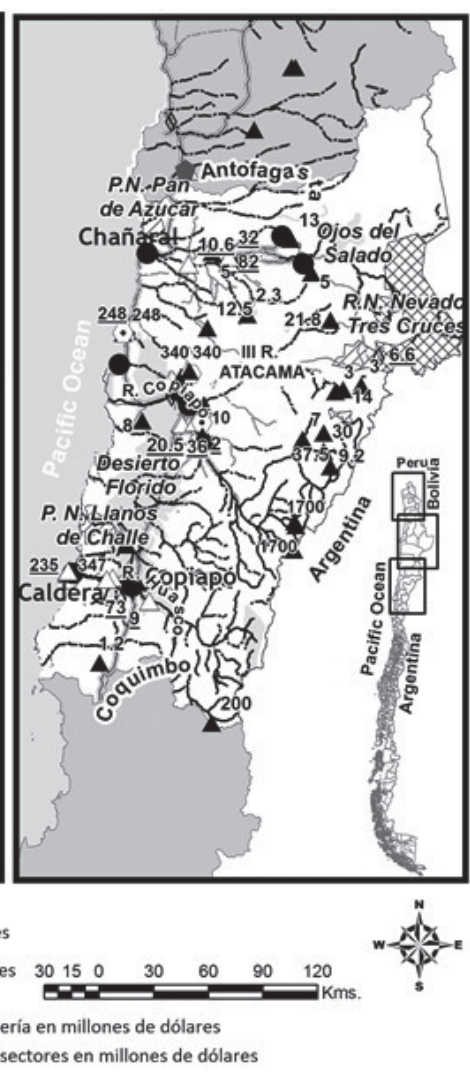

Fuente: Elaboración propia.

agua varía entre 38,5 a $193,3 \mathrm{~m}^{3}$ por tonelada de cobre fino producido, dependiendo de la tecnología de la empresa y el volumen de producción. Las compañías mineras son dueñas del 49,4\% de todos los derechos de aprovechamiento de aguas otorgados entre 1990 y 2010 (Romero et al., 2012). Además y dada la escasez o inexistencia de recargas superficiales, las aguas son extraídas crecientemente desde el subsuelo, mediante pozos profundos que muchas veces se localizan aguas arriba en las cuencas de captura de salares y lagunas o bien en las nacientes de los sistemas de drenaje superficial. Es igualmente importante señalar que la mayor parte de las aguas son almacenadas en las tierras altas y se desplazan hacia las tierras bajas como parte de acuíferos subterráneos que emergen en áreas que atraen, por lo tanto, la localización de las extracciones, que dependen principalmente de las surgencias de aguas subterráneas cuyas fuentes actuales y pasadas (recursos hídricos "azonales") no corresponden al tiempo ni espacio donde se localizan actualmente (Messerli et al.,1997; Ahumada y Faúndez, 2009).

Desde el punto de vista sociocultural, las escasas comunidades indígenas asentadas en las vertientes más altas de los Andes chilenos descansan en una actividad predominantemente agropastoril, por lo que el desecamiento de los humedales y lagunas, ya sea por la escasez de precipitaciones o por las extracciones excesivas, afecta directamente la abundancia y disposición de la vegetación de 
la cual se alimentan sus animales, lo cual ya ha ocurrido en algunas cuencas de la región de Tarapacá. En otro aspecto, las comunidades indígenas localizadas a menor altura, dependen principalmente de la agricultura, por lo que el desecamiento de las vertientes, que a su vez se alimentan de los acuíferos situados en las cuencas de mayor altura (Suzuki y Aravena, 1984; Ruz et al., 2008), afectaría el desarrollo y permanencia de esta cultura en los sectores rurales del desierto de Atacama.

Ante estos escenarios, se puede observar en la Figura $N^{\circ} 6$ que en la Región de Arica y Parinacota no existen proyectos mineros en ejecución y que en las regiones altiplánicas predominan las áreas de conservación de la naturaleza. Sin embargo, las autoridades de esta región realizan esfuerzos para desafectar 40.000 ha de tierras, actualmente clasificadas como Parques Nacionales o Reservas de la Naturaleza, para localizar proyectos mineros o bien permitir la extracción de agua subterránea que facilitaría su instalación, argumentando que "El gobierno busca impulsar en Arica una actividad sana y sustentable, responsable con el medio ambiente y los derechos indígenas, para acortar distancia con los beneficios que la gran minería ha dado al resto del Norte Grande" (El Mercurio, 21 de junio de 2010, cuerpo C, p. 7).

Las situaciones más críticas están localizadas en las regiones de Antofagasta y Atacama, que ocupan el centro y sector derecho de la figura. Por un lado, se trata de las zonas más áridas del altiplano y del desierto de Atacama, lo que disminuye aún más la disponibilidad de agua, y por otro, de las mayores concentraciones de proyectos mineros. En el caso de la región de Antofagasta se encuentran agotados los derechos de agua y la desalinización del agua de mar surge como la única opción para disponer de los recursos hídricos necesarios. Sin embargo, existen numerosos ríos, lagos y salares que se han visto severamente afectados por las extracciones de aguas superficiales y subterráneas y son igualmente numerosas las comunidades indígenas y rurales que han sido obligadas a abandonar sus asentamientos debido a la falta total de este recurso, como ha sucedido en Quillagua, localidad ubicada en el río Loa, el único que logra alcanzar la costa en medio del desierto de Atacama, que ha interrumpido su cauce debido a las extracciones practicadas aguas arriba (Budd, 2009b). Se espera que las presiones se concentren en esta década sobre áreas de conservación de la naturaleza que se encuentran especialmente en el salar de Atacama y en cuerpos de agua ubicados en las mayores alturas andinas.

En el caso de la región de Atacama, la cuenca del río Copiapó es una de las más afectadas. Debido a la altísima insolación que se registra en las áreas continentalizadas y al aumento de las precipitaciones sólidas y líquidas que ocurren en la alta cordillera andina, este valle ha logrado desarrollar cerca de 30.000 ha de cultivos de "parronales" dedicados a la producción de uva fresca o de mesa, destinada a los mercados asiáticos, norteamericanos y europeos. La alta insolación recibida por la orientación Norte-Sur de este valle y la presencia permanente de la subsidencia atmosférica, causada por el Anticiclón del Pacífico Sur, generan islas de calor, ubicadas sobre el fondo del valle y laderas de exposición norte y oeste, que garantizan no solo una extraordinaria productividad biológica, sino que también una maduración temprana de la fruta, lo que le permite acceder a los mercados internacionales antes que cualquier otra zona en el mundo. El agua requerida se obtuvo primeramente de los cursos superficiales, favorecidos por la alimentación glaciar de los ríos cordilleranos, nacidos en medio de paisajes climáticos caracterizados por temperaturas muy bajas.

Compañías del "agrobussiness" en manos de empresarios nacionales y extranjeros consiguieron la transformación de paisajes completamente áridos en extensos y continuos campos de cultivo, cuya principal limitación había sido hasta ahora la disponibilidad de agua, para lo cual se le comenzó a extraer masivamente del acuífero subterráneo. Ante la falta de modelos hidrológicos validados por la información de terreno, lo que se discute actualmente en este valle, no es el hecho de que las extracciones de agua superen a la recarga, sino el saber cuántas veces las primeras superan a las segundas. El déficit hídrico permanente ha sido hasta ahora resuelto mediante pozos profundos que han agotado recursos fósiles, presentándose como un ejemplo dramático de insustentabilidad económica, social y ambiental. 
Durante las últimas décadas, los megaproyectos mineros han irrumpido con gran ímpetu en la región de Atacama y con ello se ha generado una alta competencia por el uso del agua con la agricultura y más recientemente, por los usos urbanos en ciudades que crecen vertiginosamente por efectos de las demandas de mano de obra y servicios. En septiembre de 2011, se declaró una situación de emergencia hídrica, que significa que no se está pudiendo satisfacer las necesidades de la población y se deberán profundizar los pozos de extracción de agua subterránea. Mientras tanto, las empresas mineras se encuentran empeñadas en construir aducciones que les permitan captar directamente el agua desde pozos ubicados en torno a áreas de conservación de la naturaleza ubicadas en la alta cordillera, como sucede en los salares de Maricunga y Pedernales. Adicionalmente, se ha desencadenado un gran proceso especulativo por transferir derechos privados de agua desde el sector agrícola al minero, para lo cual se han llegado a pagar precios desconocidos en el mercado chileno y seguramente equivalentes a los más altos del mundo.

En una perspectiva multiescalar, en una forma contradictoria con la escala global de las grandes inversiones mineras realizadas por empresas trans o multinacionales, se encuentran las comunidades indígenas ancestrales, donde las relaciones ecológico-sociales a escala local implican necesariamente una organización territorial que no solo intenta optimizar los beneficios económicos de los usos del suelo, sino que además conseguir una adecuada distribución social de los mismos. De igual forma, las instituciones sociales comunitarias deben conseguir éxito en dividir socialmente la aversión a los riesgos naturales entre todos los miembros de la comunidad, que en el caso del altiplano andino, consiste especialmente en reducir la vulnerabilidad ante tales eventos e incrementar la capacidad de resiliencia frente la ocurrencia de sequías, inundaciones y ondas de frío, asociadas a nevazones y bajísimas temperaturas. Las estrategias de adaptación ante las variabilidades e incertidumbres climáticas deben de haber comenzado con la ocupación misma del territorio, entre 10.000 y 7.000 años a. C. Gundermann y González, 1989; Van Kessel, 1996, 2003; Yáñez y Molina, 2008). Van Kessel (2003) expone que alrededor del
4100 a. C. comienzan a escasear los animales (por cambios climáticos), lo que obligó a estas organizaciones sociales de características tribales a complementar su dieta con alimentos provenientes de la costa, "guarda" (almacenaje) de alimentos, construcción de canales de riego y terrazas de cultivo.

Parte importante de las estrategias territoriales de adaptación de las comunidades indígenas ante las variabilidades climáticas han consistido en diferenciar las potencialidades y limitaciones de los pisos ecológicos o cinturones de altitud de las montañas, así como explotar las condiciones topoclimáticas de facetas tales como fondos de valle, laderas según exposición y posición topológica y relieve relativo de las altiplanicies, en especial para evitar ocupar lugares donde se acumula el aire frío. Murra (1972) Ilamó a esta construcción territorial como complementariedad ecológica de los pisos verticales y Zimmerer (2003) las denominó como modelo de zonas atadas. Se trata de categorías integrativas de los factores que determinan la productividad agrícola, como topografía, clima y vegetación. Los habitantes de las comunidades, conocedores de las diferencias topoclimáticas y sus variaciones estacionales e interanuales, trasladan los ganados auquénidos (Ilamas y alpacas, especialmente) entre las tierras bajas y altas, en la búsqueda de los pastos que se encuentran en las franjas riparianas de arroyos y ríos y sobre las laderas de las montañas, adaptabilidades que se analizarán en las localidades de Caquena y Cancosa.

Caquena, cuyos circuitos de transhumancia se pueden apreciar en la Figura $N^{\circ} 7$, está localizada en la comuna de Putre, Región de Arica-Parinacota. Con una población de 112 habitantes al año 2002, pertenecientes principalmente a la etnia indígena aimara, la comunidad se encuentra situada en una subcuenca del río Cosapilla en los 4.400 m.s.n.m. y registra como principal actividad económica la ganadería de auquénidos, especialmente Ilamas. La mayoría de los animales de la comunidad se concentran en la parte baja del humedal, desde donde van siendo trasladados según la disponibilidad de pastos, ya sea hacia los terrenos de control exclusivo por parte de la comunidad, o bien sobre áreas que comparten con comunidades vecinas y que se activan ante cualquier déficit 
en la capacidad de carga ganadera. Durante el invierno, la posibilidad de mantener los animales en las tierras planas se torna inviable debido a la acumulación del aire frío y al congelamiento del agua, suelos y pastos, por lo que se hace necesario trasladarlos hacia sitios más abrigados, no obstante que se pueden localizar a mayor altura. Estas decisiones de evitar los riesgos mayores exigen un conocimiento de las condiciones climáticas por parte de los habitantes locales que difícilmente pudiera encontrarse entre los habitantes urbanos o entre quienes les sustituyan finalmente en sus áreas de ocupación una vez que hayan migrado definitivamente. La climatología social es parte fundamental del conocimiento local y las estrategias de mitigación y adaptación frente a sus variabilidades temporales y espaciales.
Las estrategias de adaptación socioculturales conformadas por estas formas ancestrales de manejo territorial de los recursos naturales asociados a las variaciones locales de los climas o topoclimáticas a escala de cuencas y subcuencas, se están viendo amenazadas no solo por los eventuales efectos de mayores cambios y variabilidades climáticas, sino que también por transformaciones sociodemográficas, culturales, económicas y políticas. Destaca, en primer lugar, el severo despoblamiento y envejecimiento de prácticamente la totalidad de los habitantes del altiplano chileno, arrastrado desde hace siglos. Asimismo, y desde hace unas décadas, la competencia por la propiedad y control del agua entre la minería y la que se requiere para regar los pastizales y cultivos agrícolas de las comunidades indígenas, se contrapone al modelo de zonas atadas, que supone la

Figura $\mathrm{N}^{\circ} 7$

Circuitos de transhumancia ganadera de auquénidos de la comunidad aimara de Caquena.

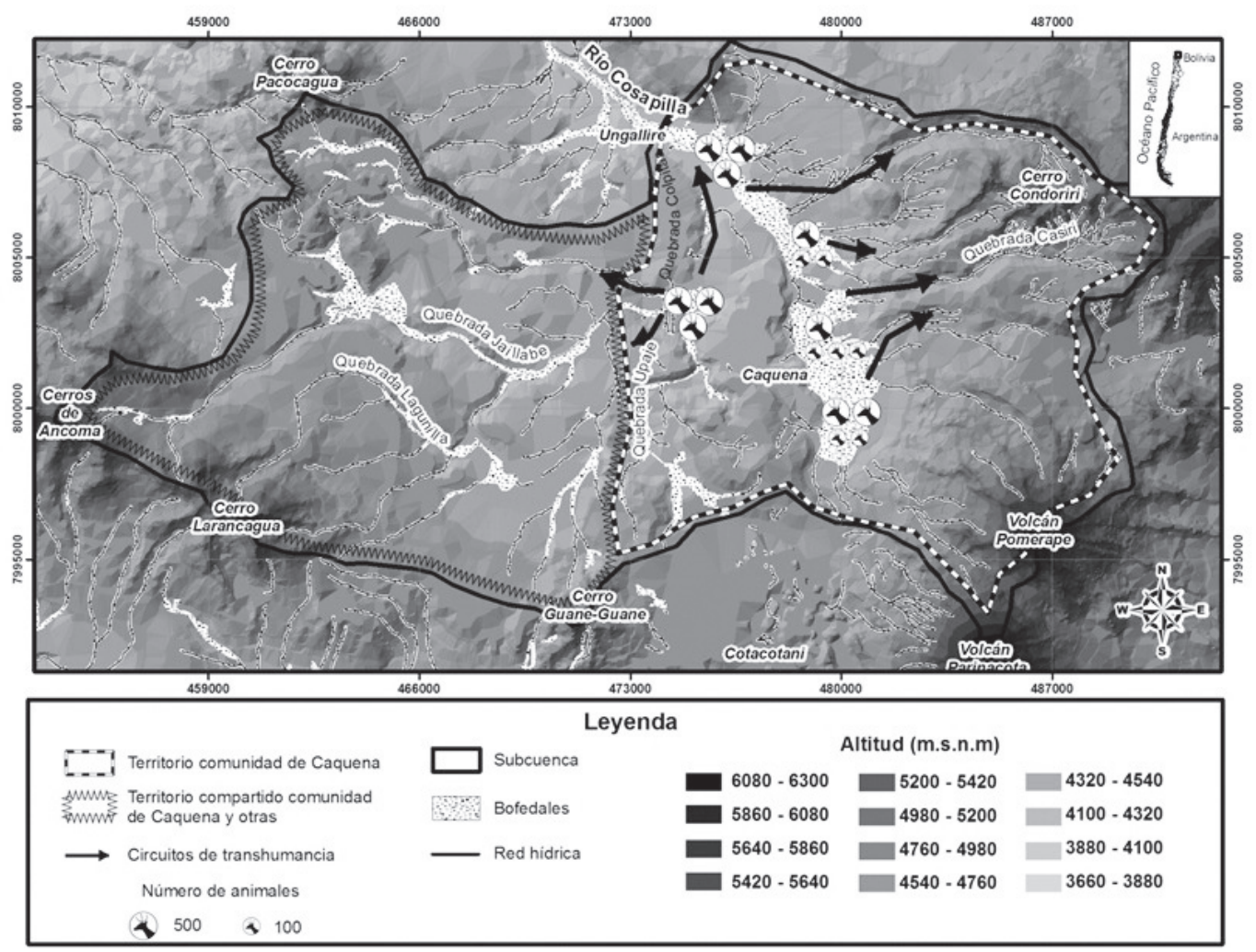

Fuente: Elaboración propia sobre la base de información de terreno. 
Figura $\mathrm{N}^{\circ} 8$

Circuitos de transhumancia ganadera de auquénidos de la comunidad aimara de Cancosa

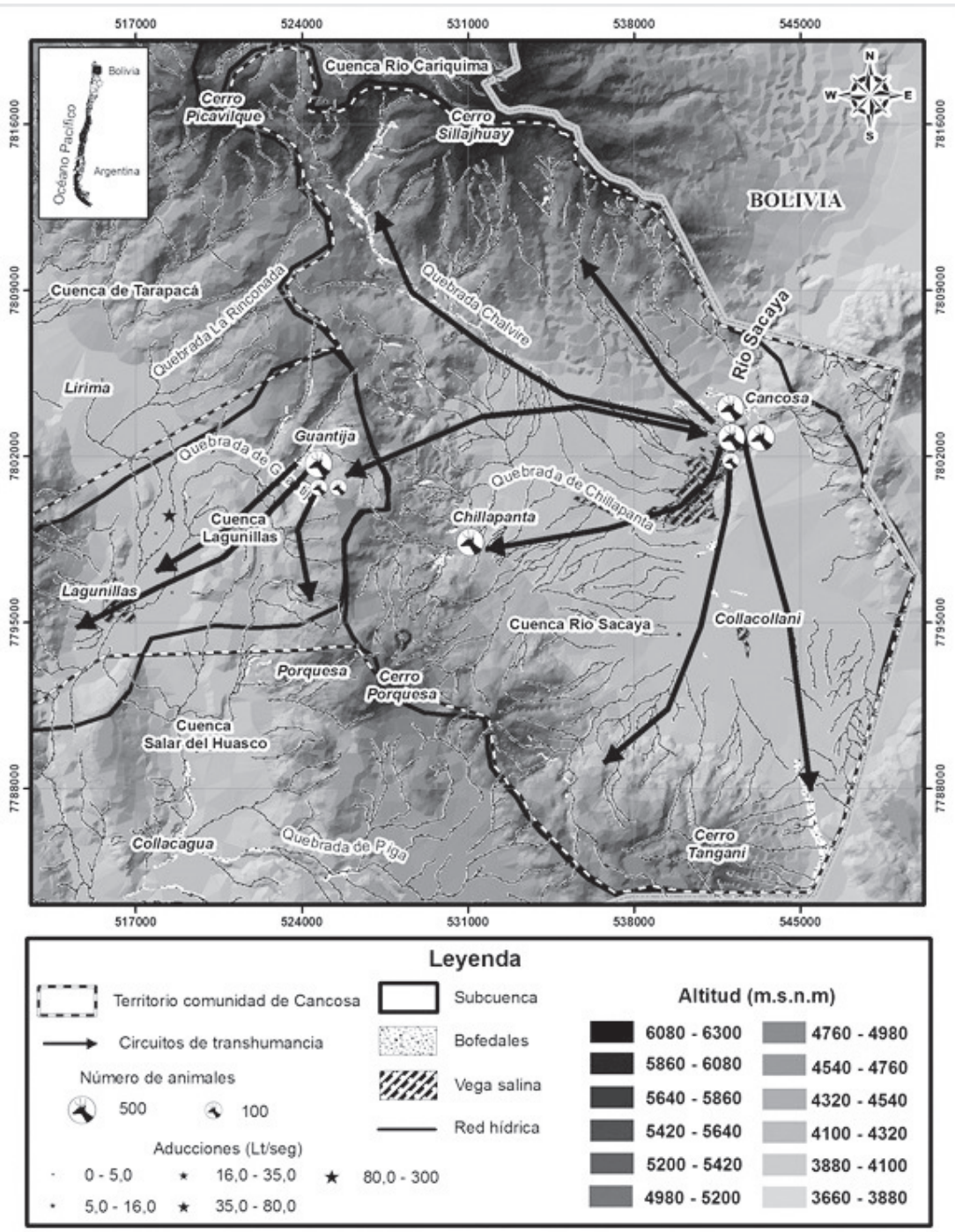

Fuente: Elaboración propia sobre la base de información de terreno.

existencia de terrenos comunitarios o de propiedad común, que facilitan el acceso libre a los pisos altitudinales, componentes socioculturales que se enfrentan a la necesidad de privatizar los recursos naturales para asegurar su compra y venta en el mercado.

A lo anterior se deben agregar situaciones conflictivas surgidas al interior de las propias comunidades, ante las negociaciones y actuaciones que se han establecido entre las numerosas organizaciones que han surgido o activado para enfrentar las presiones sobre los territorios y sus recursos. Estas competencias se aprecian claramente en la comunidad de Cancosa (Figura $N^{\circ} 8$ ), situada en las cuencas de Sacaya y Lagunillas, a 3.950 m.s.n.m, con una población permanente de 18 personas al año 2002 y económicamente dedicada a la ganadería de auquénidos y el cultivo de quínoa. En esta comunidad el impacto de la actividad minera ha ido más allá de la apropiación física de los recursos hídricos, puesto que no solo se desecó el humedal de Lagunillas, alterando con ello la ocupación de la cuenca por los comuneros que poseen 
sus animales en el sector de la Laguna de Guantija, sino que además, la negociación y acuerdo con la Compañía Minera Cerro Colorado por la extracción de aguas subterráneas en el sector Pampa Lagunilla, ha causado profundas divisiones internas debido a los mayores o menores beneficios económicos que habrían obtenido unos u otros.

\section{Conclusiones}

El análisis climático geográfico resulta imprescindible para poder comprender algunos de los problemas ecológico-sociales que afectan al desierto de Atacama y que, tal como se ha presentado, requiere de visiones multiescalares y multidisciplinarias que tornen evidente relaciones entre la sociedad y la naturaleza y entre los propios grupos sociales que se han ido estableciendo en el territorio en largos y cortos períodos de tiempo. El análisis de las relaciones espacio-temporales entre la ocurrencia de lluvias en el altiplano andino y la amazonía, ejecutada a través del Monzón Sudamericano, no solo demuestra la extraordinaria complejidad de los eventos climáticos que se presentan en nuestros territorios, sino que además, la necesidad de integrar geográficamente procesos y formas que hasta ahora, han sido abordados al interior de cada uno de los países como si las fronteras político-administrativas se prolongaran hasta el comportamiento de los climas regionales e implicaran un límite al propio conocimiento de la climatología. Este trabajo constituye una invitación a formar redes de investigación sobre la climatología sudamericana.

El paisaje del desierto de Atacama, tan diferente al de la selva amazónica, es, sin embargo, una expresión de un conjunto de relaciones espaciales o teleconexiones, desencadenadas por los sistemas de circulación atmosférica en sus interacciones con la superficie terrestre, su topografía, coberturas y usos del suelo. Por ello, es tan relevante para la climatología chilena conocer los efectos que tendrá sobre sus climas la deforestación de la selva amazónica como para la brasileña anticipar las sequías o las ondas de frío causadas por un fenómeno La Niña.

En el caso de las cuencas y altiplanos andinos, las poblaciones que ocupan históri- camente diferentes nichos ecológicos aprendieron a manejar los climas con sus riesgos y beneficios para poder sobrevivir hasta nuestros días, contando con sólidos conocimientos locales vinculados a sus formas cotidianas de vida. Durante los últimos 500 años se ha tratado de convencerlos de su ignorancia científica y de la superioridad cultural de los actores foráneos. Sin embargo, se enfrentan hoy con el posible agotamiento definitivo de recursos esenciales tanto para nuestra organización social, como para la de ellos, que por ocupar esos espacios por más tiempo y por depender intrínsecamente de sus recursos, aprendieron a manejar su abundancia y escasez, sus fortalezas y vulnerabilidades, administrando los riesgos y gestando resiliencias, distribuyéndolos socioespacialmente. ¿No sería el momento de la climatología geográfica de buscar las conexiones socioclimáticas? ¿No tendríamos acaso que aprender acerca de los riesgos y los desastres naturales y resiliencia tanto de las poblaciones ancestrales andinas como de las amazónicas?

La dinámica vigente e histórica de los sistemas ambientales y las proyecciones de los cambios climáticos futuros requieren visiones y acciones estratégicas de planificación y gestión ambiental, que identifiquen en el mediano y largo plazo, y en forma amplia, las diversas alternativas que puedan existir para compatibilizar la conservación del agua y la naturaleza de los humedales, con las demandas sociales y económicas que se deberán enfrentar en forma creciente, proponiendo acciones que contribuyan y no contravengan su sustentabilidad.

La salud de los ecosistemas, particularmente de los humedales altoandinos, no solo es esencial para la conservación de la diversidad biológica sino también para el bienestar de las comunidades humanas y el desarrollo económico de la región. Esta visión reconoce las funciones y los servicios ambientales desde el punto de vista climático, que proveen las montañas, los humedales y altiplanos andinos, como parte integral del desarrollo sustentable y que, por lo tanto, exigen un enfoque de planificación, gestión y valoración mucho más amplio y complejo que el que se tiene en la actualidad, de naturaleza solo económica. La gestión de estos ecosistemas no debe solo responder a su condición de 
recursos naturales necesarios para la sociedad, sino que comprometerse además con la conservación de su riqueza y diversidad biológica, con los procesos ecológicos e hidrológicos y servicios ambientales que prestan sus ecosistemas y con el desarrollo de las comunidades sociales que los han habitado por milenios.

En este sentido, se puede decir que en la Región de Arica y Parinacota, aun no se observan grandes impactos causados por la minería, posibilitado por sus extensos territorios protegidos por parques y reservas naturales (a través de los cuales se pretendía establecer soberanía en periodos anteriores). Sin embargo, por las condiciones de disponibilidad del recurso hídrico, las crecientes demandas y precios de los minerales en el mercado internacional y los esfuerzos el Gobierno por desafectar áreas protegidas por el SNASPE, se prevé el arribo de proyectos mineros de gran y mediana minería. Estas inversiones son vistas, por el Gobierno y por ciertos sectores económicos, como el mecanismo "salvador" de los sectores socioeconómicamente deprimidos del norte de Chile, no obstante, y por los impactos en las condiciones físiconaturales y socioculturales que han causado los yacimientos de la gran minería localizados en la región de Tarapacá, se hace estrictamente necesario desarrollar instrumentos integrales de gestión de los territorios, que orienten y administren la compatibilidad de las múltiples actividades presentes en estas regiones, asegurando la permanencia de las comunidades indígenas del altiplano, la conservación de territorios de gran riqueza natural y sociocultural, así como también, el aprovechamiento sustentable de las riquezas minerales presentes en estas zonas, cuando corresponda.

La necesidad de perfeccionar las visiones y objetivos territoriales es uno de los aspectos que debiera contribuir a la sustentabilidad de las regiones y lugares localizados en las tierras altas del desierto de Atacama, que, como se sabe, es considerado uno de los más áridos del mundo y que enfrenta la singular paradoja de que junto a su aparente limitación de recursos hídricos, dispone de ecosistemas de alta riqueza, presenta una de las más interesantes muestras de adaptación y diversidad sociocultural y como si no fuera suficiente, concentra una de las mayores reservas de minerales metálicos y no metálicos del mundo. Bajo estas circunstancias, es evidente que los planes y programas destinados a conseguir su desarrollo sustentable, deben comenzar reconociendo la unicidad de sus paisajes naturales y socioculturales y sus áreas de influencia, que son producto de un sistema socioecológico complejo e incierto, que ha desarrollado mecanismos de adaptación y resiliencia ante los cambios y variabilidades climáticos, incluyendo entre otros factores, la distribución espacial o territorial de los riesgos como un orden primario y fundamental.

\section{Referencias bibliográficas}

ACEITUNO, P. Elementos del Clima en el Altiplano Sudamericano. Revista GeofísicaIPGH, 1996, N 44, p. 37-55.

AHUMADA, M. y FAÚNDEZ, L. Guía descriptiva de los sistemas vegetacionales azonales hídricos terrestres de la ecorregión altiplánica (SVAHT). Santiago de Chile: Ministerio de Agricultura, 2009.

ALVES, L. M. Clima da Região CentroOeste do Brasil. In: CAVALCANTI, I.F. de A.; FERREIRA, N.J.; DA SILVA, M.G.A.J. y DIAS, M.A.F. DA SILVA (orgs.). Tempo e Clima no Brasil. São Paulo: Oficina de Textos, 2009, p. 235-24.

BAUER, C. Bringing wáter markets down to earth. World Development, 1997, Vol. 25, $N^{\circ}$ 5, p. 639-56.

BAUER, C. Siren Song. Resources for the Future. Washington, D.C., 2004, p. 92-99.

BUDDS, J. Power, nature and neoliberalism: the political ecology of water in Chile. Journal of Tropical Geography, 2004, Vol. 25, $\mathrm{N}^{\circ} 3$, p. 322-42.

BUDDS, J. Whose Scarcity? The hydrosocial cycle and the changing waterscape in La Ligua river basin, Chile. In: GOODMAN, M. \& EVERED, K. (editors). Contentious Geographies. Ashagate: Farnham, 2008, p. 58-98,

BUDDS, J. Contested H2O: Science, policy and politics in water resources manage- 
ment in Chile. Geoforum, 2009a, № 40, p. 418-430.

BUDDS, J. The 1981 water code: The impacts of private tradable water rights on peasant and indigenous communities in Northern Chile. In: ALEXANDER, W. (editor). Lost in the long transition: Struggles for social justice in neoliberal Chile. Lanham: Lexington Books, 2009b, p. $35-55$.

COMISIÓN NACIONAL DEL MEDIO AMBIENTE (CONAMA). Estudio de la variabilidad climática en Chile para el siglo XXI. Santiago de Chile: Departamento de Geofísica, Facultad de Ciencias Físicas y Matemáticas, Universidad de Chile. Informe Final, 2006.

GAN, M. A.; KOUSKY, V. E. \& ROPELEWSKY, C. F. The South America monsoon circulation and its relationship to rainfall over West-Central Brazil. Journal of Climate, 2004, Vol. 17, p. 47-66.

GAN, M.; RODRIGUES, L. C. e RAO, V. B. Monção na América do Sul. In: CAVALCANTI, I. F. de A.; FERREIRA, N.J.; DA SILVA, M.G.A.J. e DIAS, M.A.F. DA SILVA (orgs.). Tempo e Clima no Brasil. São Paulo: Oficina de Textos, 2009, p. 297-316.

GARREAUD, R.; VUILLE, M. \& CLEMENTS, A. The climate of the Altiplano: Observed current conditions and past change mechanisms. Paleo3, 2003, No 3.054, p. 1-18.

GUNDERMANN, H. y GONZÁLEZ, H. Cultura aymara. Artesanías tradicionales del altiplano. Santiago de Chile: Serie Patrimonio cultural chileno, Colección Culturas Aborígenes, Departamento de Extensión Cultural del Ministerio de Educación, Museo Chileno de Arte Precolombino, 1989.

LAGOS, G. Eficiencia del uso del agua en la minería del cobre. Santiago de Chile: Centro de Estudios Públicos -CEP, Serie de Documentos de Trabajo Gestión del agua en la minería, 1997, N²73, p. $55-67$.

LAU, K.M. \& ZHOU, E.J. Rainfall regimes and interannual variability of South American summer monsoon. In: VI International Confe- rence on Southern Hemisphere Meteorology and Oceanography. Santiago de Chile, 2000.

MARENGO, J.A.; AMBRIZZI, T. e SOARES, W. R. Jato de Baixos Níveis ao longo dos Andes. In: CAVALCANTI, I.F. de A.; FERREIRA, N.J. ; DA SILVA, M.G.A.J. e DIAS, M.A.F. DA SILVA (orgs.). Tempo e Clima no Brasil. São Paulo: Oficina de Textos, 2009, p. 169-180.

MELO, A.B.C. de; CAVALCANTI, I.F. de A. e SOUZA, P. Zona de Convergencia Intertropical do Atlántico. In: CAVALCANTI, I.F. de A.; FERREIRA, N.J.; DA SILVA, M.G.A.J. e DIAS, M.A.F. DA SILVA (orgs.). Tempo e Clima no Brasil. São Paulo: Oficina de Textos, 2009, p. 25-41.

MÉNDEZ, M.; CORVACHO, O. Y ALBORNOZ, C. Catastro de derechos de aguas otorgados en la Región de Arica y Parinacota. Estudio de la demanda por recursos hídricos por parte de las personas y comunidades indígenas de la región de Arica y Parinacota. Análisis de las diversas posibilidades de satisfacción de esta demanda. Arica: URAQUI LTDA y CONADI Arica y Parinacota, 2011.

MESSERLI, B.; GROSJEAN, M. \& VUILLE, M. Water availability, protected areas and natural resources in the Andean Desert Altiplano. Mountain Research and Development, 1997, Vol. 17, N 3, p. $229-238$.

MOLINA, F. Competing rationalities in water conflicts: Mining and the indigenous community in Chiu Chiu, El Loa Province, northern Chile. Singapore Journal of Tropical Geography, 2012, №33, p. 93-107.

MORAN, J.M. \& MORGAN, M.D. Meteorology. The atmosphere and the science of weather. Minneapolis: Burgess Publishing, 1986.

MURRA, J. El 'control vertical' de un máximo de pisos ecológicos en la economía de las sociedades andinas. En: Visita de la Provincia de León de Huánuco en 1562 por Iñigo Ortiz de Zúñiga. Huánuco: Universidad HermilioValdizán, 1972, Vol. 2, p. 427-476.

NOOA/NCEP. Cold \& Warm Episodes by Season. Change to the Oceanic Niño Index 
(ONI). Disponbile en Internet: http://www. cpc.ncep.noaa.gov/products/analisys.

PRUDHAN, S. Commodification. In: CASTREE, N.; DEMERITT, D.; LIVERMAN, D. \& RHOADS, B. A Companion To Environmental Geography. London: Wiley \& Blackwell, 2009, p. 123-142.

ROMERO, H. Agua, poder y discursos en el conflicto socio-territorial por la construcción de represas hidroeléctricas en la Patagonia Chilena. Anuario de Estudios Americanos, Vol. 66, No 2, 2009a, p.81-103.

ROMERO, H. Global Changes and economic globalization in The Andes.Challenges for developing nations. In: PSENNER, R.; LACKNER, R. \& BORSDORF, A. (Editors). Global Change and Sustainable Development in Mountain Regions. Innsbruck: Alpine Space - Man \& Environment, Vol. 7, Innsbruck University Press, 2009b, p. 71-95.

ROMERO, H.; MENDONÇA, M.; MENDEZ, M. y SMITH, P. Multiescalaridade, Relações Espaciais e Desafios Ecológicos-sociais da Climatologia Sudamericana. O caso do Deserto de Atacama. Revista Brasileira de Climatologia, 2011, № 8.24 .

ROMERO, H.; MÉNDEZ, M. \& SMITH, P. Mining development and environmental injustices in The Atacama Desert (Northern
Chile). Environmental Justice, 2012, Vol. 5, No 12 , p. $70-76$

RUZ, R.; DÍAZ, A. y GALDAMES, L. Población andina de las Provincias de Arica y Tarapacá. El censo inédito de 1866. Arica: Ediciones Universidad de Tarapacá, 2008.

SUZUKI, O. y ARAVENA, R. Hidrología Isotópica y el Recurso Agua del Sector Esmeralda-Pica-Matilla. Santiago de Chile: Comisión Chilena de Energía Nuclear, 1984.

VAN KESSEL, J. La cosmovisión aymara. Etnografía: sociedades indígenas contemporáneas y su ideología. Santiago de Chile: Ed. Andrés Bello, 1996.

VAN KESSEL, J. Holocausto al progreso: Los Aymará de Tarapacá. Iquique: IECTA, 2003.

YÁÑEZ, N. y MOLINA, R. La gran minería y los derechos indígenas en el norte de Chile. Santiago de Chile: Ediciones LOM, 2008.

ZIMMERER, K. Environmental Zonation and Mountain Agriculture in Peru and Bolivia: Socioenvironmental Dynamic of Overlapping Patchworks and Agrodiversity Conservation. In: ZIMMERER, K. \& BASSETT, T. Political ECology. An Integrative Approach to Geography and Environment-Development Studies. London: The Guilford Press, 2003, p. 137-158. 
